\title{
DIREITO E DEVER DE RESISTÊNCIA OU PROGRESSO PARA MELHOR POLITICA, DIREITO E HISTÓRIA EM I. KANT*
}

José N. Heck**

SINTESE - Para Kant, a luta pelo aprimoramento do direito é travada com as armas da argumentação. Trata-se de emancipar a comunidade juridica da tutela oriunda do senhorio violento das origens, rumo ao Estado republicano. O processo desemboca na constituiçăo de um Estado estabelecido pela união de uma multidão de seres humanos submetida a leis de direito, no qual 0 povo exerce, na figura de seus representantes, a soberania e os poderes da República estão comprometidos com a eficácia do direito. 0 artigo expõe tópicos do pensamento político do pensador alemāo e destaca traços relevantes da filosofia da história no Kant tardio. O trabalho visa contribuir para o debate político, juridico e filosófico atual sobre globalização e o futuro do Estado nacional de direito.

PALAVRAS-CHAVE - 0 sumo bem político. Direito de resistência. Filosofia da história. Kant tardio.
ABSTRACT - According to Kant, the struggle for the improvement of right must be fought with the weapons of reasoning. What is ultimately at stake is the emancipation of the juridical community from the violent rule of masters, towards a republican State. This process culminates in the constitution of an established State through the union of a multitude of human beings under the rule of law, in which the people exert sovereignty through their representatives and the powers of the Republic comply with the efficiency of the law. This article expounds themes in the political thought of the German philosopher and highlights the relevant contributions of the later Kant to the philosophy of history. It seeks thus to contribute to the ongoing political, juridical and philosophical debate on globalization and the future of the national democratic state.

KEY WORDS - The political highest good. Right to resistance. Philosophy of history. The later Kant.

É convicção inabalável de Kant que o direito só se aprimora no interior de uma dada ordem estabelecida.

A negação do direito de resistência, apostrofada pelo filósofo alemão, decorre de um simples argumento. A possibilidade de resistir legalmente ao monopólio do poder implica ter autoridade para determinar as condições, mensurar os critérios e escolher os meios para a própria desobediência. Com isso, cada recalcitrante poli-

* Texto da Aula Inaugural do Programa de Pós-Graduação em Filosofia da PUCRS, proferida pelo autor em 16 de agosto de 2004.

** Doutor. Professor titular da UFG e da UCG; pesquisador do CNPq 1B. Atualmente Pró-Reitor de Pós-Graduação e Pesquisa da UCG e Professor Visitante da PUCRS.

\begin{tabular}{|l|l|l|l|l|l|} 
VERITAS & Porto Alegre & v. 49 & n. 4 & Dezembro 2004 & p. 803-824 \\
\hline
\end{tabular}


tico assenhoreia-se do poder de decisão e adquire privilégios de soberano. Caso haja quem no Estado detenha a força, não há ninguém que possa em relação ao mesmo reivindicar direitos de resistência, a não ser que não seja ele o titular supremo do poder estatal, mas, sim, quem se the opõe no comando do Estado. Segundo Kant, para que um povo estivesse autorizado a oferecer resistência, necessário seria uma lei pública que lhe facultasse resistir, vale dizer, a legislação maior teria que encerrar uma disposição de que não é soberana, e que tornasse o povo, por um e mesmo critério, soberano na qualidade de súdito em relação àquele ao qual está submetido. "Isto é contraditório", conclui o doutrinador jurídico, "e a contradição se evidencia tão logo quando se pergunta a quem cabe ser o juiz nessa disputa entre o povo e o soberano [...]". !

No instante em que a atuação pacificadora do Estado é ajuizada como pressuposto incondicional da obediência dos cidadãos, a suposta relevância jurídica da gênese histórica dos Estados perde significado. A força vinculadora dos ordenamentos jurídicos estatais desfigura os meios violentos que 0 atual detentor da autoridade porventura empregou outrora na tomada de poder. Para Kant, a procedência histórica da constituição civil contém uma idéia enquanto princípio da razão prática, segundo o qual "o poder legiferante constituído deve ser obedecido, seja qual for a sua origem". ${ }^{2}$

Mesmo confrontado com o regicídio, a execução formal do monarca, Kant mantém a duras penas a argumentação jurídica. O filósofo alemão evita dialetizar a origem do direito com uma noção de moralidade que o legitime para todo e sempre de forma absoluta. A submissão incondicional da vontade popular a uma vontade soberana é Tat, ou seja, constitui fato político enquanto gesto histórico. Tal vontade só pode instalar-se no poder pelo domínio da força e fundamenta, em primeira mão, um direito público. Conceder aos cidadãos o direito de resistir ao legado original do poder é ostensivamente contraditório, uma vez que anula a instância que determina o que é para ser e o que não é para ser publicamente de direito. "Este princípio", escreve Kant na frase conclusiva do anexo à Doutrina do direito, "já está presente a priori na idéia de uma constituição civil, isto é, num conceito da razão prática". E arremata: "Embora nenhum exemplo na experiência seja adequado para ser submetido a esse conceito, ainda assim nenhum exemplo deve contradizê-lo como norma". ${ }^{3}$

KANT. Metaphysische Anfangsgründe der Rechtslehre 320. Hrsg. von B. Ludwig. Hamburg: Meiner, 1986, p. 142. "(W)elches sich widerspricht, und wovon der Widerspruch durch die Frage alsbald in die Augen fällt, wer denn in diesem Streit zwischen Volk und Souverän Richter sein sollte $[\ldots] "$.

2 Ibidem 318 , p. 140. "[...] der jetzt bestehenden gesetzgebenden Gewalt gehorchen zu sollen; ihr Ursprung mag sein, welcher er wolle",

3 Ibidem 372, p. 200. "†...] und dieses Prinzip liegt schon a priori in der Idee einer Staatsverfassung überhaupt, d.i. in einem Begriffe der praktischen Vemunft; dem zwar adäquat kein Beispiel in der Erfahrung untergelegt, werden kann, dem aber auch, als Norm, keine widersprechen muss". 
Sejam fundadores da República ou senhores da última Revolução, Kant abstém-se de macular os titulares do poder soberano com os estigmas de um pecado original de estirpe político-filosófica. Igual ao que ocorre num cenário anárquico, quando a razão habilita cada homem a forçar seu semelhante a entrar com ele num estado comunitariamente legal, quer dizer, constituir pela força uma ordem primordial de paz, Kant coloca sob a guarda da idéia de constituição aqueles que se apoderam, em todos os tempos, dos poderes constituídos quer pela força, chantagem ou revolução. O doutrinador do direito racional é coerente ao saudar a Revolução Francesa, muito embora repudie a decapitação de Luís XVI como pecado contra o Espírito Santo. Enquanto ordem estabelecida, a vitória da Grande Revolução descerra o pano para uma nova arrancada jurídica ao longo da história, no progresso constante para melhor por parte do gênero humano.

De acordo com Kant, a luta pelo aprimoramento do direito é travada com as armas da argumentação. Trata-se do empenho de emancipar a comunidade jurídica da tutela oriunda do senhorio violento das origens, rumo a um Estado republicano entranhado na liberdade. O processo desemboca na constituição de um Estado estabelecido pela união de uma multidão de seres humanos submetida a leis de direito, no qual o povo exerce, na figura de seus representantes, a soberania, e os poderes da República ficam comprometidos com a realização e a eficácia do direito.

\section{Direito, humanismo e violência}

Um direito de resistência significa, em Kant, o colapso de toda e qualquer política de segurança jurídica. O Estado que o prevê, assegura ou tolera oficialmente importa para dentro de si a violência e condena seus cidadäos à volta do estado natural. Na medida em que o direito de resistência inviabiliza a resolução de conflitos no seio do Estado, a existência de uma norma positiva que a legitime equivale à dissolução do Estado. Nesse caso, a conduta de resistência tem a cobertura do direito positivo, mas assim mesmo continua de todo ilegítima, pois, segundo Kant, o comportamento recalcitrante "torna insegura toda a constituição jurídica e abre as portas para o estado de uma plena ausência de leis (status naturalis), onde todo o direito cessa ou, pelo menos, deixa de ter efeito". ${ }^{4}$

A tese kantiana da proibição à resistência adquire relevância frente ao impasse do contratualismo político nos portais da Modernidade, de precisar garantir, por um lado, a adesão dos cidadãos à autoridade estatal e, por outro, ser obrigado a estabelecer parâmetros de justiça para o mando politico do Estado. Para um olhar atento, a aparente convergência de critérios contratualistas tăo-só prolonga indefinidamente a anarquia do estado de natureza, na medida em que a observância

KANT, Uber den Gemeinspruch 301. Hrsg. Von H. Klemme. Hamburg: Meiner, 1992, p. 34. "[...] Das Volk doch durch diese Art, ihr Recht zu suchen, im höchsten Grade unrecht getan habe, weil dieselbe $[. .$.$] alle rechtliche Verfassung unsicher macht, wo alles Recht aufhört, wenigstens Effekt$ zu haben, einführt". 
dos deveres contratuais está a fortiori condicionada à justiça de leis previamente submetidas ao controle das normas estabelecidas. O estado natural não é, desde Hobbes, outra coisa do que a indecisão entre a legitimação do poder político e a vigência de normas amparadas pela justiça. Sob este aspecto, a interdição ao direito da resistência ratifica em Kant o Estado como figura racional por excelência, não menos do que como figuração contratual.

A silhueta racional do Estado kantiano é bem distinta da racionalidade moral do filósofo alemão. Enquanto a moralidade postula a revolução nas mentes dos homens, a política é feita, ocorre e opera sob a lei da continuidade, ou seja, no campo da moral impera a lei proibitiva de qualquer compromisso entre o que é falso ou verdadeiro, correto ou incorreto, bom ou mau e assim por diante, ao passo que no universo da política a continuidade histórica constitui pressuposto do mais ínfimo e discreto progresso de justiça.

Este não é o caso da tradição humanista que nos vem de Cícero. De acordo com a obra De officiis, um republicano "nada tem em comum com os tiranos, razão por que também não pode ser contra a natureza matá-los". ${ }^{5} \mathrm{Na}$ história política do Ocidente, configurada pela tradição jusnaturalista, o humanismo honra invariavelmente a supremacia do direito natural sobre o direito positivo, quando se trata de sustentar um direito suprapositivo à resistência.

$\mathrm{Na}$ esteira de Hobbes, o filósofo alemão rompe com esse legado político no pólo doutrinário mais edificante do humanismo europeu, a saber, na encarnação diabólica do tirano. A par dessa tradição, todo governante que pervertesse 0 bem comum devia sofrer resistência e, caso não se curvasse à felicidade coletiva, teria que ser afugentado do poder ou ser morto. Onde os humanistas vêem flores nascendo de cadáveres, Kant narra o retorno "ao estado da anarquia com todos os seus horrores $[\ldots]^{\prime \prime}{ }^{6}$ quando um partido inflige injustiça ao outro no seio do povo e os sublevados buscam impor à força uma constituição mais opressiva do que aquela contra a qual se revoltaram. O filósofo esclarece:

Inexiste, por conseguinte, direito de sedição (seditio), e menos ainda de rebelião (rebelIio), e menos do que tudo o mais existe um direito contra o chefe do Estado como pessoa individual (o monarca), de atacar sua pessoa ou mesmo sua vida (monarchomachismus sub specie tyrannicidi), sob o pretexto de que abusou de sua autoridade (tyrannis).

5 CICERO, Tulius, De officiis III, 6. Oeuvres complètes. Trad. do latim por M. Nisard. Paris: Dislot, 1859 , p. 85 (edição bilingüe). "Nulla enim societas nobis cum tyrannis [...]; neque est contra naturam spoliare eum, si possis, quem est honestum necare [...]".

6 KANT. Uber den Gemeinspruch 302. Hrsg, von H. Klemme. Hamburg: Meiner, 1992, p. 35. "Hier tritt nun der Zustand der Anarchie mit allen ihren Greueln [...]" .

7 Idem. Metaphysische Anfangsgründe der Rechtslehre 320. Hrsg. von B. Ludwig. Hamburg; Meiner, 1986, p. 142. "(A)lso kein Recht des Aufstandes (seditio), noch weniger des Aufruhrs (rebellio), am allerwenigsten gegen ihn als einzelne Person (Monarch), unter dem Vorwande des Missbrauchs seiner Gewalt (tyrannis), Vergreifung an seiner Person, ja an seinem Leben (monarchomachismus sub specie tyrannicidi)". 
A posição de Kant contra um direito à revolução é tão visceral que o filósofo mantém o princípio anti-revolucionário do direito racional, mesmo onde o direito positivo garante aos cidadãos o poder da resistência, revolta ou revolução, tão logo os pressupostos constitucionais estejam preenchidos. Tal conduta insurrecional é a única ação legal perante a qual Kant sustenta a superioridade do direito racional, mesmo que, no caso, tratar-se-ia de uma resistência em conformidade à constituição, vale dizer, o respectivo soberano não poderia nem mesmo alegar que está sofrendo alguma injustiça. Ao limitar, rigorosamente, a excelência jurídica do direito racional à salvaguarda dos poderes constituídos contra uma sublevação amparada numa lei positiva revolucionária, o filósofo alemão honra a política como esfera humana onde vigora a lei da continuidade do projeto do Esclarecimento enquanto libertação da superstição. Na medida em que interdita revoluções apenas em nome de leis juspositivas, o direito racional é eximiamente iluminista por avalizar o simplesmente negativo, no qual o Kant tardio flagra a quintessência do Iluminismo, ${ }^{8}$ um negativo sem correspondente positivo, algo assim como o lema mefistofélico da Modernidade.

Na Paz perpétua, o filósofo alemão insiste que uma configuração jurídica incipiente é melhor do que nenhuma, mesmo que coadune apenas minimamente com o direito. ${ }^{9}$ Ele distingue entre uma situação jurídica embrionária e uma situação que se encontra nos devidos termos juridicos. Embora a primeira não seja achada inteiramente conforme, o doutrinador a considera suficientemente articulada a ponto de poder exigir obediência. Essa constelação jurídica elementar, Kant a situa entre o estado natural e o estado constitucional e, como tal, corporifica a negação de ambos, na medida em que não é mais um estado natural e ainda não é um Estado de direito, ou seja, trata-se do Estado enquanto evento natural, quando individuos dispersos são submetidos às determinações de uma vontade qualquer que os agregue num povo unido.

Por mais deficiente que seja, a fundação empírica de um Estado converte a idéia da constituição em representação política e coloca, assim, em vigor a matriz das relações normativas da convivência humana. Tão logo haja um senhorio políti$\mathrm{co}$, que atue em nome da lei e detenha o monopólio do poder, ele deve ser aceito como exigência racional da idéia de constituição. Para Kant, nem o dever de obediência dos súditos unidos pela força e tampouco o direito de mando de fundadores exitosos de um Estado tem sua razão de ser na mera existência do poder político. A origem jurídica de ambos está única e exclusivamente na constituição da sociedade de direito. Uma ordem politica surgida por meios violentos não constitui argumento contra a autoridade estatal estabelecida. Seja usurpador, revolucioná-

s Idem. Kritik der Urteilskraft 158. Hrsg. von K. Vorländer, Hamburg: Meiner, 1968, p, 145-146. "Befreiung vom Aberglauben heisst Aufklärung" [...]; (nota de rodapé): "[...] so muss das bloss Negative (welches die eigentliche Aufklärung ausmacht) in der Denkungsart (zumal der offentlichen) zu erhaiten oder herzustellen sehr schwer sein".

s Idem. Zum ewigen Frieden 373 (nota de rodapé). Hrsg. von H.-F. Klemme. Hamburg: Meiner, 1992, p. 87. "[...] weil doch irgendeine rechtliche, obzwar nur in geringem Grade rechtmässige Verfassung besser ist als gar keine [...]". 
rio, golpista ou dominador, nenhum titular do poder precisa temer que a maneira como se apodera do título lhe seja incriminado ou justifique a resistência contra o seu senhorio político. Kant escreve:

Ademais, no caso do êxito de uma revolução e o estabelecimento de uma nova constituiçăo, a falta de legitimidade com a qual esta principia e é posta em prática não pode liberar os súditos da obrigação de acatar a nova ordem das coisas como bons cidadãos e não podem deixar de honestamente obedecer à autoridade que detém agora o poder. 10

Uma vez pacificados os homens, a origem da convivência torna-se insignificante. "A razão jurídico-estatal prescreve ao súdito o esquecimento", escreve Kersting; e acrescenta: "Não há neste mundo tribunal que pudesse incriminar o detentor da força". " Embora incida sobre o direito, Kant reconhece a revolução vitoriosa por dar, como poder ordenador supremo, uma nova oportunidade ao contínuo e jamais interrompido aperfeiçoamento do direito. Não importa se na origem do Estado atual tenha sido celebrado um contrato qualquer ou o poder tenha sido imposto primeiro pela força e apenas depois exercido mediante a lei, seja como for, não cabe a um povo já submetido à lei civil perscrutar, segundo Kant, "sobre a origem da autoridade suprema à qual está submetido, isto é, o súdito nāo deve raciocinar, em termos práticos, a respeito da origem dessa autoridade $[\ldots]^{\prime \prime}{ }^{12}$

Enquanto a conexăo entre lei moral e a esperança de ser feliz, ou seja, a exata proporção entre felicidade, justiça e moralidade postula Deus e imortalidade como constituintes de um reino moral infenso à morte, a história é para Kant constitutiva do direito voltado à realização progressiva das idéias do republicanismo e da paz perpétua, ou seja, a prática política em consonância com a moral perfaz uma "doutrina do direito em exercício" (ausübende Rechtslehre). ${ }^{13}$

Nada há, para o filósofo do direito racional, o que possa reverter ou sustar a continuidade do progresso histórico do direito. Não há educação capaz de corromper de tal forma um ser humano, a ponto de torná-lo irreflexivamente mau, desprovido de sensibilidade, heteronômico por definiçăo racional e para quem todos os demais homens tornar-se-iam supérfluos. Mesmo os chamados malvados

10 Idem. Metaphysische Anfangsgründe der Rechtslehre 323. Hrsg. von B. Ludwig. Hamburg; Meiner, 1986, p. 145. "Übrigens, wenn eine Revolution einmal gelungen und eine neue Verfassung gegnundet ist, so kann die Unrechtmässigkeit des Beginnens und der Vollführung derselben die Untertanen von der Verbindlichkeit, der neuen Ordnung der Dinge sich, als gute Staatsburger, zu fügen, nicht befreien, und sie können sich nicht weigem, derjenigen Obrigkeit ehrlich zu gehorchen, die jetzt die Gewalt hat".

11 KERSTING. Wohlgeordnete Freiheit. Immanuel Kants Rechts- und Staatsphilosophie. Frankfurt a/M: Suhrkamp, 1993, p. 475. "(D)ie staatsrechtliche Vernunft verordnet dem Untertan Vergessen. In dieser Welt gibt es keinen Gerichtshof, der den Gewalthaber zur Verantwortung ziehen konnte".

12 KANT. Metaphysische Anfangsgninde der Rechtslehre 318. Hrsg. von B. Ludwig. Hamburg; Meiner, 1986, p. 140. "Der Ursprung der obersten Gewalt ist für das Volk, das unter derselben steht

[...] unerforschlich: d.i. der Untertan soll nicht über diesen Ursprung [...] vernünfteln".

13 Idem. Zum ewigen Frieden 371. Hrsg. von H.-F. Klemme. Hamburg: Meiner, 1992, p. 82. "[...] mithin kann es keinen Streit der Politik als ausubender Rechtslehre mit der Moral [...] geben". 
inatos (geborene Bösewichter), "com uma maneira de pensar incapaz de qualquer melhora", ${ }^{14}$ não quebram a continuidade da história que sucessivamente apazigua o estado de natureza com um estado jurídico que progressivamente se põe em conformidade com o direito.

Tão-somente ao abordar o justiçamento de Carlos I e Luís XVI, o filósofo alemão detém-se na silhueta do mal mais extremo, que "infunde horror numa alma imbuida da idéia dos direitos dos seres humanos" ${ }^{15}$ Kant se pergunta como pode ser explicado esse sentimento de horror, que não é um sentimento de simpatia, "mas um sentimento moral resultante da completa subversão de todos os conceitos de direito" ${ }^{16}$ Kant compara a execução formal dos dois monarcas com o que "os teólogos chamam de pecado inexpiável, quer neste mundo, quer no outro (crimen immortale, inexpiabile), ${ }^{17}$ uma maldade expressa, um crime lesa-pátria, inteiramente sem propósito, que, mesmo sendo impróprio aos humanos cometê-lo, "não é cabível que seja ignorado num sistema de moral (a despeito de ser tão-só a idéia do mal mais extremo (obzwar blosse Idee des Äusserst-Bösen)". ${ }^{18}$ Para o doutrinador alemão, a máxima que conduz ao justiçamento de uma autoridade estatal é oposta à lei não apenas por ato de omissão. Com a execução formal do monarca o povo não só age contrariamente à lei senão que acaba diametralmente em oposição à mesma, quer dizer, a máxima de sua conduta afigura-se contraditória em relação à lei, "pois é como se o Estado", escreve Kant, "cometesse suicídio". ${ }^{19}$

Mesmo assim, o filósofo alemão não admite que haja abismos históricos na esfera do direito, rechaça a malignidade na origem da ordem jurídica e mantém constante a seqüência tendencial para melhor da parte do gênero humano. Também na pior injustiça a humanidade continua mantendo viva a idéia do direito. Para Kant, todo ordenamento jurídico vigente, mesmo tendo a violência por origem, mas não a norma, é mais salutar que a ausência de qualquer forma de justiça e está, assim, em consonância com a máxima maior de pensar por si mesmo, voltada invariavelmente para a autopreservação da razão, em luta contra a atuação do gênio, do sectário, do iluminado, do fanático e de toda sorte de superstição e devaneio.

${ }^{14}$ Idem. Kritik der praktischen Vernunft 178-179. Hrsg, von K. Vorländer. Hamburg: Meiner, 1967, p. 116. "[...] dass man sie für geborene Bösewichter und gänzlich, was die Denkungsart betrifft, für unbesserlich hält [...]".

Idem. Metaphysische Anfangsgründe der Rechtslehre 322. Hrsg. von B. Ludwig. Hamburg; Meiner, 1986, p. 143. "Die formale Hinrichtung ist es, was die mit Ideen des Menschenrechts erfuilte Seele mit einem Schaudern ergreift [...]".

to Ibidem. "[...] sondem moralisch, der gänzlichen Umkehrung aller Rechtsbegriffe ist".

17 Ibidem. "(W)as die Theologen diejenige Sünde nennen, welche weder in dieser noch in jener Welt vergeben werden kann".

18 Ibidem, p. 144. "(U)nd doch (obzwar blosse Idee des Äusserst-Bösen) in einem System der Moral nicht zu übergehen".

19 Ibidem, p. 145. "(A)ls ein vom Staate an ihm verübter Selbstmord [...]" 
O princípio da não-contradição é configurado no cosmopolitismo políticojurídico kantiano pelo perfil do inimigo injusto. Segundo Kant, é inimigo injusto o Estado cuja vontade, expressa publicamente, "revela uma máxima segundo a qual, se fosse convertida em regra universal, qualquer condição de paz entre os povos não apenas tornar-se-ia impossivel, mas o estado de natureza deveria ser perpetuado ad aeternum" ${ }^{20} \mathrm{O}$ direito moderno transige com a suposta contradiçäo entre direito e injustiça, mas não suporta a negação que a violência impōe ao direito. Enquanto a interdição kantiana de um direito à resistência ocorre no plano da contraposição entre direito e injustiça no seio de Estados estabelecidos, o dever de combater o inimigo injusto localiza-se no cerne da não-contradição entre direito e violência. Ainda que a figura do inimigo injusto integre a doutrina do direito dos povos, a constituição de alguns países preceitua o direito dos cidadãos de resistir passiva e ou ativamente aos detentores da força, quando a lei maior está sendo ostensivamente vilipendiada pelos titulares dos poderes estatais.

\section{Razão prática e filosofia política}

À luz dos postulados da razão pura prática é mister assumir como objeto real de nossa vontade o progresso que avança ao infinito em direção à conformidade plena entre moralidade e felicidade.

Tal conjunção perfeita constitui, em Kant, o sumo bem. Este se torna possível, segundo o filósofo, "sob a pressuposição de uma existência e personalidade do mesmo ente racional que perdura ao infinito (a qual se chama imortalidade da alma)".". Além desse progresso ad infinitum, indemonstrável como proposição teórica, os princípios da razão prática asseguram igualmente que a felicidade acaba destinada exclusivamente àqueles que a merecem. Graças a uma simples razão imparcial, cujo pressuposto encontra-se na existência de uma causa adequada a esse efeito, a razão pura prática postula e a fé racional (Vernunftglaube) reconhece "a existência de Deus como necessariamente adequada à possibilidade do sumo bem [...]". ${ }^{22}$ A existência de Deus, como causa suprema da natureza, consolida o segundo elemento do sumo bem. Ele equivale, para Kant, ao sábio governo que distribui com justiça a felicidade da qual os homens precisam, isto é, de modo exatamente proporcional à moralidade do ser humano.

Os postulados da razão pura prática acerca da imortalidade da alma e da existência de Deus satisfazem plenamente às exigências de seres racionais finitos cuja moralidade não contém analiticamente em si a felicidade, mas cuja razão reivindi-

20 Ibidem 349, p. 171. "[...] Es ist derjenige, dessen öffentlich [...] geäusserter Wille eine Maxime verrät, nach welcher, wenn sie zur allgemeinen Regel gemacht würde, kein Friedenszustand unter Völkern möglich, sondern der Naturzustand verewigt werden müsste".

${ }^{21}$

KANT. Kritik der praktischen Vemunft 220. Hrsg, von K. Vorländer. Hamburg: Meiner, 1967, p. 141. "Dieser unendliche Progressus ist aber nur unter Voraussetzung einer ins Unendliche fortdauemden Existenz und Persönlichkeit desselben vernünttigen Wesens (welche man die Unsterblichkeit der Seele nennt) möglich".

22 Ibidem 224, p. 143. "[...] die Existenz Gottes als zur Möglichkeit des höchsten Guts [...] notwendig gehörig postulieren". 
ca que sejam felizes na exata medida em que são dignos da felicidade. $\mathrm{O}$ filósofo alemão é quanto a isso incisivo. Por um lado, afirma que "felicidade e moralidade são, quanto à sua espécie, dois elementos do sumo bem totalmente diversos e que, portanto, a sua combinação não pode ser conhecida analiticamente" ${ }^{\text {23 }} \mathrm{e}$, por outro, deixa claro que um ser carente de felicidade e que fosse também digno dela, mas mesmo assim não participante dela, "não pode coexistir com o querer perfeito de um ente racional que ao mesmo tempo tivesse todo o poder, ainda que pensemos um tal ente apenas a título de ensaio". ${ }^{24}$

Como a perfeição moral, ajustada à perfeita felicidade requer tempo interminável, o progresso do qual Kant fala no domínio dos postulados da razão pura prática refere-se ao mundo e ao além, uma vez que o progresso infinito inicia aqui e se estende para todo e sempre eternidade afora.

Na medida em que cumprem sua função, os dois postulados não respondem, porém, adequadamente à demanda do imperativo categórico que prescreve ao indivíduo neste mundo o dever incondicional de obedecer à lei moral. O descompasso e contratempo da fé racional pura na perfeição moral (imortalidade da alma) e na harmonia entre felicidade e moralidade (existência de Deus) com a lei moral qua elemento legislador da razão pura prática enquanto liberdade dos seres finitos è de molde a induzir uma aparente contradição entre as constantes frustrações da felicidade humana no cumprimento dos deveres neste mundo e a plena proporcionalidade da moralidade à felicidade no mundo do porvir. Por que, afinal, os seres humanos fariam bem em perseguir fervorosamente o sumo bem na Terra, quando está excluído para todo e sempre, segundo Kant, que neste mundo se alcance a perfeição moral correspondente à felicidade que lhe cabe? De resto, a natureza não costuma ser uma mãe pródiga na distribuição da felicidade a seus filhos.

Ao longo da obra kantiana, antes e depois da segunda Crítica, há registros vários de que o filósofo tinha percepção do risco de que o progresso humano se afigure ilusório, quiçá seja não mais que uma quimera envolta nas teias fictícias de veleidades futuras, em suma, o progresso poderia näo passar de uma referência extra-racional recheada de mil e uma futilidades.

Na última proposição do ensaio sobre uma idéia de história universal, de 1784 , o autor se pergunta para que serve exaltar a majestade e a sabedoria da criação se desesperamos da história do gênero humano a ponto de acharmos que seu pleno desenvolvimento racional somente pode ser esperado num outro mundo. ${ }^{25}$ No trabalho sobre o significado de orientar-se no pensamento, de 1786 , o filósofo insiste que é preciso impedir que o conceito do soberano bem, junta-

${ }^{23}$ Ibidem, 203, p. 130. "Glückseligkeit und Sittlichkeit zwei spezifisch ganz verschiedene Elemente des höchsten Guts sind und ihre Verbindung also nicht analytisch erkannt werden (kann)".

24

Ibidem 199, p 128. "Denn der Glückseligkeit bedürftig, ihrer auch würdig, dennoch aber derselben nicht teilhaftig zu sein, kann mit dem vollkommenen Wollen eines vemüntigen Wesens, welches zugleich alle Gewalt hätte, wenn wir uns auch nur ein solches zum Versuche denken, gar nicht zusammen bestehen".

25 KANT. Idee zu einer allgemeinen Geschichte in weltbürgerlichen Absicht. In: Kleinere Schniften zur Geschichtsphilosophie, Ethik und Politik. Hrsg. von K. Vorländer. Hamburg: Meiner, 1973, p. 19-20. 
mente com toda a moralidade, seja considerado um puro ideal. ${ }^{26} \mathrm{Na}$ terceira parte (contra M. Mendelssohn) do chamado Dito comum (1793) e em O conflito das faculdades (1798), Kant observa que não admitir o contínuo progresso do gênero humano faz com que o mero vaivém do bem e do mal da espécie humana sobre o globo tem que ser visto como uma simples comédia farsante (Possenspiel). ${ }^{27}$

Como o gênero humano, a natureza e a história humana não são per se iguais a indivíduos e tampouco podem ser destinatários do imperativo categórico ou estar carentes de felicidade, o progresso moral e o governo justo, porquanto constituintes dos postulados da imortalidade da alma e da existência de Deus, são inconseqüentes tout court em relação aos sujeitos históricos do progresso que não sejam indivíduos de carne e osso.

O tipo de progresso que envolve o sumo bem moral não é o mesmo que "poderá conduzir os humanos enquanto espécie", escreve Kant, "a uma aproximação contínua ao sumo bem político, ou seja, à paz perpétua". ${ }^{28}$ Não apenas os objetos do progresso são diferentes, mas sobretudo as alternativas a serem descartadas năo são as mesmas. O sumo bem moral dispensa os monstros dos teósofos e místicos, todas as espécies de sonhos, bem como liberta o homem do antropomorfismo como fonte de superstição, fanatismo, preconceito e intuições suprasensiveis, ${ }^{29}$ ao passo que o sumo bem político protege o gênero humano dos devaneios da guerra justa, da indiferenciação entre violência e injustiça, bem como do maniqueísmo moralista, de modo que um uso analógico dos postulados da imortalidade da alma e da existência de Deus no dominio do progresso para melhor por parte do gênero humano não vem ao caso. ${ }^{30}$

Enquanto a primeira e a segunda Crítica alocam o sumo bem no mundo do além, a terceira Crítica o localiza, como bem maior do mundo (das Weltbeste), no universo das coordenadas sublunares. Após afiançar que "somos determinados a priori pela razão, no sentido de promover com todas as nossas forças o maior bem do mundo", o filósofo explicita que tal bem consiste na ligação do maior bem dos

${ }^{26}$ Idem. Was heisst: sich im Denken orientieren? In: Immanuel Kant. Textos seletos (edição bilíngüe). 2. ed. Petrópolis: Vozes, 1986, p. 83.

27 Idem. Uber den Gemeinspruch: das mag in der Theorie richtig sein, taugt aber nicht für die Praxis - III. Vom Verhältnis der Theorie zur Praxis im Volkerrecht (Gegen Moses Mendelssohn). Hrsg, von H.-F. Klemme, Hamburg: Meiner, 1992, p. 42; Der Streit der Fakultäten. Hrsg. von K. Reich. Hamburg: Meiner, 1975, p. 81.

Idem. Metaphysische Anfangsgründe der Rechtslehre 355. Hrsg. von B. Ludwig. Hamburg; Meiner, 1986, p. 178. "[...] in kontinuierlichen Annäherung zum höchsten politischen Gut, zum ewigen Frieden, hinleiten kann".

Cf. KANT. Kritik der praktischen Vernunft 217-218/244-245. Hrsg, von K. Vorländer. Hamburg: Meiner, 1967, p. 139/156.

Outra posição: LINDSTEDT, David. Kant: Progress in Universal History as a Postulate of Practical Reason. Kant-Studien. Jhrg. 90, Heft 2., 1999, p. 143: "Two postulates, then, are needed, which are analogous to the postulates of immortality and God. The first, nature as working providentially, functions analogously to the postulate of the existence of God in the second Critique [... . But a second postulate, similar to the immortality of the individual, is needed so that one may hope for the achievement of perfect morality". 
seres racionais do mundo "com a suprema condição do bem nos mesmos, isto é, da felicidade universal com a moralidade maximamente conforme a lei"; ${ }^{31}$ e acrescenta:

Por isso é exigido para a realidade teórica objetiva do conceito de fim terminal (Endzweck) proposto a priori, mas também que a criaçäo, isto é, o próprio mundo, possua um fim terminal segundo a sua existência. [...]. Pois se a criação possui toda ela um fim terminal, então não podemos pensá-la de outro modo senão de que ele tem de entrar em acordo com o fim moral (o único que torna possivel o conceito de um fim). [...]. Por isso possuímos um fundamento moral para pensarmos num mundo também um fim terminal da criação. ${ }^{32}$

Ao final da primeira parte da Crítica da faculdade do juízo, Kant formula o critério de acordo com o qual o gosto declara válido determinado prazer para a humanidade em geral e não apenas para o sentimento privado de cada ser humano em particular, ao escrever: "[...] o gosto é, no fundo, uma faculdade de ajuizamento da sensificação de idéias morais (mediante uma certa analogia da reflexão sobre ambas as coisas)". ${ }^{33}$ Tal derivação do prazer estético do sentimento moral vem precedida de uma breve e compacta digressão sobre um feixe de referências políticas alusivas à humanidade, sociabilidade, coletividade duradoura e coerção legal.

Ao abordar os humaniora como conhecimentos prévios para toda arte bela no mais alto grau, o filósofo alemão faz uma dupla referência aos estudos humanísticos da Antigüidade grega e romana. Num primeiro momento, expõe que essas obras de arte não remetem a conceitos, mas estão impregnadas com as faculdades do ânimo, "presumivelmente porque humanidade significa de um lado o universal sentimento de participação e, de outro, a faculdade de poder comunicar-se íntima e universalmente ${ }^{34}$, propriedades que juntas constituem a sociabilidade, caracteres próprios ao homem e pelos quais, segundo Kant, nos distinguimos dos seres animais. Num segundo momento, o filósofo avalia o acervo artístico dos gregos e romanos como produto de certo modo humano de conviver e, por isso mesmo, caudatário de traços políticos que lembram não menos a Grande Revolução do que a antiga grandeza política de Atenas e Roma.

${ }^{31}$ KANT, Kritik der Urteilskraft 429. Hrsg. von K. Vorländer. Hamburg: Meiner, 1968, p. 325. "Wir sind a priori durch die Vernunft bestimmt, das Weltbeste, welches in der Verbindung des grossten Wohls der vemünftigen Weltwesen mit der höchsten Bedingung des Guten an denselben, di. der allgemeinen Glückseligkeit mit der gesetzmässigsten Sittlichkeit besteht, nach allen Kräften zu befördem".

Ibidem 430, p. 325 e 327. "Zur objektiven theoretischen Realität also des Begriffs von dem Endzwecke vemünftiger Weltwesen wird erfordert, dass nicht allein wir einen uns a prion vorgesetzten Endzweck haben, sondern dass auch die Schöpfung, d.i.. die Welt selbst ihrer Existenz nach einen Endzweck habe [...]. Denn hat die Schöpfung überall einen Endzweck, so können wir ihn nicht anders denken als so, dass er mit dem moralischen (der allein den Begriff von einem Zwecke möglich macht) übereinstimmen müsse. [...]. Also haben wir einen moralischen Grund, uns an einer Welt auch einen Endzweck der Schöpfung zu denken".

Ibidem 263, p. 217. [...] der Geschmack im Grunde ein Beurteilungsvermögen der Versinnlichung sittlicher Ideen (vermittelst einer gewissen Analogie der Reflexion über beide) ist".

34 Ibidem 262, p. 216. "[...] vermutlich, weil Humanität einerseits das allgemeine Teilnehmungsgefühl, andererseits das Vermogen, sich innigst und allgemein mitteilen zu können, bedeutet". 
Reportado à época e a povos cujo impulso à sociabilidade legal os levou a constituir uma coletividade duradoura, conjugando liberdade e coerção mais por dever do que por medo, Kant escreve que uma tal época e um tal povo "teriam que inventar primeiro a arte da comunicação recíproca das idéias da parte mais culta com as idéias da parte mais inculta $[\ldots]^{35}$ e, assim, inventar o meio termo entre cultura e natureza, "que constitui também para o gosto, enquanto sentido humano universal, o padrão de medida correto, impossível de ser indicado por nenhuma regra universal" ${ }^{36}$

O filósofo não nomeia nem a invenção à qual se refere nem identifica o povo que a pôs no mundo. Como a invenção não é para Kant deduzida de uma regra geral senão que advém do acordo da ampliação e do refinamento da parte mais culta com a natural simplicidade e originalidade da parte mais inculta, ${ }^{37}$ pode-se supor que o filósofo esteja visualizando a Declaração Geral dos Direitos Humanos, aprovada pelos membros dos três Estados-Gerais em sua primeira reunião na condição de Assembléia Nacional, meio ano antes do surgimento da terceira Crítica. ${ }^{38}$

A hipótese encontra amparo numa passagem da Antropologia em perspectiva pragmática, onde os homens são vistos como seres inventivos que, à medida que aumentam os males que uns infligem aos outros, não vêem outra saída pela frente senão aquela de colocar o sentido privado de alguns sob o sentido comum unificado de todos e decidem assim, muito embora a contragosto, submeter-se à disciplina da coerção civil, à qual tão-somente se sujeitam de acordo com leis promulgadas por eles próprios e, à luz da consciência que têm disso tudo, "sentem-se enobrecidos por fazer parte de um gênero que é adequado à destinação do homem, de maneira como a razão lhe apresenta o destino humano na feição ideal" . ${ }^{39}$

\section{Da terceira crítica à história}

As leituras políticas da terceira Crítica e de outros textos kantianos, feitas por H. Arendt num seminário sobre filosofia política de Kant (1970), na New School for Social Research, adotam o juizo estético, em perspectiva reflexionante-teleológica, como modelo do juízo político. ${ }^{40} \mathrm{Na}$ contramão da proposta benjaminiana de politi-

${ }^{35}$ Ibidem 263, p. 2716. "ein solches Zeitalter und ein solches Volk musste die Kunst der wechselseitigen Mitteilung der Ideen des ausgebildesten Teils mit dem roheren [...] zuerst erfinden $[\ldots]^{\prime \prime}$.

36 Ibidem. "(W)elches den richtigen, nach keinen allgemeinen Regeln anzugebenden Massstab auch für den Geschmack als allgemeinen Menschensinn ausmacht".

37 Ibidem. [...] Abstimmung der Erweiterung und Verfeinerung der ersteren [des ausgebildetsten Teils, J.N.Heck] zur natürlichen Einfalt und Originalität der letzteren [mit dem roheren, J.N.Heck].

38 ARNOLD, Markus. Die harmonische Stimmung aufgeklärter Bürger. Zum Verhältnis von Politik und Ästhetik in Immanuel Kants "Kritik der Urteilskraft". Kant-Studien. Jhrg. 94, Heft 1, 2003, p. 24-25.

39 KANT. Anthropologie in pragmatischer Hinsicht 329-330. Hrsg, von K. Vorländer. Hamburg: Meiner, 1980, p. 285-286. "[...] durch dies Bewusstsein sich veredelt fühlen, nämlich zu einer Gattung zu gehören, die der Bestimmung des Menschen, so wie die Vernunft sie ihm im Ideal vorstellt, angemessen ist".

40 ARENDT, Hannah. Lectures on Kant's political philosophy. Ed. by R. Biener. Chicago: University of Chicago Press, 1982; The life of mind. 2 v. New York: H. B. Jovanovich, 1978. 
zação da arte, a estetização arendtiana da política neutraliza o papel determinante da Paz perpétua e Doutrina do direito em favor dos juizos reflexionantes estéticos, que partem do caso em busca da regra. Paradigmáticas são as análises de Arendt acerca do espectador da Revolução Francesa, "tomado", segundo Kant, "por um desejo de participação que beira o entusiasmo"."

Arendt extrai de um elenco de textos kantianos, por vezes com mais de dez anos entre si, o que chama de filosofia política de Kant, sem registrar o contexto e a temática diferenciada dos trabalhos abordados. $\mathrm{O}$ eixo que confere identidade a seus estudos sobre o pensamento político kantiano é a conexão entre juízos morais e senso comum em acepção comunitário-estética, vale dizer, a normalização do juízo político que pervade os chamados afazeres humanos (anthropon pragmata) do são-entendimento (der gemeine Menschenverstand), tema predileto na tradição do bios politikos aristotélico e com o qual Kant retoma, no parágrafo 40 da terceira Crítica, o texto "Resposta à pergunta: que é Esclarecimento?" (1784). ${ }^{42}$

A índole do espectador revolucionário arendtiano é exemplarmente moral. Os caracteres da publicidade, da generalidade, da imparcialidade e, por fim, do entusiasmo, predicados por Arendt ao espectador da Revolução Francesa em $O$ conflito das faculdades, ilustram na verdade a frase conclusiva da "Crítica da faculdade de juízo estética" (Crítica da faculdade do juízo, 1 Parte), onde Kant diz

que parece evidente que a verdadeira propedêutica para a fundação do gosto seja o desenvolvimento de idéias morais e a cultura do sentimento moral, já que somente se a sensibilidade concordar com ele pode o verdadeiro gosto tomar uma forma determinada e imutável. ${ }^{43}$

Mesmo se as análises arendtianas do pensamento político de Kant tivessem encarado o conceito de sociabilidade legal (gesetzliche Geselligkeit), ${ }^{44}$ continuaria sendo um anacronismo decifrar a figura do espectador revolucionário kantiano, em $O$ conflito das faculdades, preso aos juízos reflexivos da terceira Crítica. Diferentemente

${ }^{41}$ KANT. Der Streit der Fakultäten. Hrsg. von K. Reich. Hamburg: Meiner, 1975, p. 84. "(D)iese Revolution, sage ich, findet doch in den Gemütern aller Zuschauer $[. .$.$] eine Teilnehmung dem$ Wunsche nach, die nahe an Enthusiasmus grenzt [...]". Cf. TERRA, Ricardo. É possivel defender a legalidade e ter entusiasmo pela revoluçāo? Notas sobre Kant e a Revoluçăo Francesa. Passagens: estudos sobre a filosofia de Kant. Rio de Janeiro: Editora UFRJ, 2003, p. 101-129; Juízo político e prudência em Ả paz perpétua. ROHDEN, Valerio. (Org.). Kant e a instituição da paz. Porto Alegre: Editora da UFRGS/Goethe-Institut, 1997, p. 22-232.

42 GOUDELI, Kyriaki. Kant's Reflective Judgement: The Normalisation of Political Judgement. KantStudien. Jhrg. 94, Heft. 1, 2003, p. 31. "Kant's Critique of Judgement has been proved to be a resourceful text of major significance for contemporary debates on aesthetics, politics and epistemology. Its implicit political implications have been mainly broached by H. Arendt's innovative reading".

${ }^{43}$ KANT. Kritik der Urteilskraft 463. Hrsg. von K. Vorländer. Hamburg: Meiner, 1968, p. 216. "(S)o leuchtet ein, dass die wahre Propädeutik zur Gründung des Geschmacks die Entwicklung sittlicher Ideen und die Kultur des moralischen Gefühls sei, da, nur wenn mit diesem die Sinnlichkeit in Einstimmung gebracht wird, der echte Geschmack eine bestimmte unveränderliche Form annehmen kann",

4. Cf. ROHDEN, Valerio. Sociabilidade legal. Uma ligação entre direito e humanidade na 3. Crítica de Kant. Analytica, v. 1, n. 2, 1994, p. 97-106. 
do encaminhamento comunitánio-estético, dado por Arendt ao espectador da Grande Revolução, M. Foucault vê na segunda seção de $O$ conflito das faculdades a continuidade de "Was ist Aufklärung?" Enquanto as reflexões arendtianas sobre arte e política pöem toda a história humana aos cuidados do gosto como sensus communis, Foucault identifica na continuidade kantiana do Esclarecimento a pergunta acerca de notre actualité, de le champ actuell des expériences possibles, em suma, de une ontologie du présent, une ontologie de nous-mêmmes [... $]^{4 .}$.

Ao deixar imergir a história humana no gosto, enquanto idéia do sentido comunitário (gemeinschaftlichen Sinnes), a intérprete não acompanha o posicionamento do filósofo frente a um acontecimento de nosso tempo, de modo que não percebe, como Kant, que a "revolução de um povo pleno de espírito" (Die Revolution eines geistreichen Volks) equivale a um signo histórico (Geschichtszeichen) para os espectadores, não lhes significando mera partilha de sentimentos ligados a uma representação dada, carente da mediação de um conceito.

"O que é Esclarecimento?" articula um discurso moral, e não jurídico. Pensar por si mesmo é tomar a vontade por princípio. Ousar fazer uso do próprio entendimento equivale a usar a vontade por dever, recusando-se a recorrer a critérios alheios aos motivos que movem a ação. Kant observa a atuação de dois tipos de atores: de um lado, a grande massa, ein grosser Haufen, la multitude aveugle rousseauniana e, de outro, o homem esclarecido, der Selbstdenkende, l'homme eclaré et indépendante do genebrino. Ambos os tipos são constituídos de agentes racionais e atuam sob o regime da moralidade kantiana. O primeiro é preguiçoso, covarde e culpado pela menoridade em que vive de bom grado. Enquanto ser racional, ele não tem a quem culpar pela situação, pois é livre igual aos outros. Ele é um atestado vivo de que sua liberdade está na origem do estado tutelado em que se encontra. A razão demonstra sua autonomia na possibilidade de revertê-la, ou seja, a heteronomia não lhe é estranha, motivo pelo qual só pode ser sustada, cada vez, com base na primeira. O segundo é, ele próprio, responsável por não continuar comodamente, sendo livre, vivendo sob a tutela de outrem. Ele faz uso do entendimento, aceita o desafio racional, decidido e corajoso, e não se submete a outra autonomia senão à de sua razão. Por saber ousar, dele será o futuro; para Kant, a razão tem nele o sujeito do progresso histórico.

A crítica é uma arma da moral do Esclarecimento porque pensar ou agir sem conseqüências não é nem crítico nem moral. Aqueles que se satisfazem cumprindo ordens não pensam e agem de maneira irracional, mas suas ações e raciocínios não alteram o mecanismo da obediência. Quem faz uso de seu entendimento para tornar-se senhor de outros, mantendo em vida preceitos e fórmulas de uma perpétua menoridade, não é esclarecido. A crítica é a única arma esclarecida porque faz bem a seus usuários sem precisar fazê-lo à custa de quem dela não faz uso. Como privilégio da razão, a crítica prejudica tão pouco quanto a razão pode fazer mal. Em conseqüência, a crítica esclarecida não recorre à força nem exerce pressão.

45 FOUCAULT, Michel, "Qu' est-ce que les Lumières?". Dits et écrits IV (1980-1988). Paris: Gallimard, 1994, p. 687. 
"Uma revolução", escreve Kant, "poderá talvez trazer a queda do despotismo pessoal ou da opressão ávida de lucros ou de domínios, porém nunca trará a verdadeira reforma no modo de pensar" ${ }^{46} \mathrm{~A}$ objeção kantiana à revolução é de caráter moral, pois "apenas novos preconceitos, assim como os velhos, servirão como corrente de cabresto para conduzir a grande massa destituída de pensamento". ${ }^{47}$ Imposta pela força, a revolução apenas substitui velhos por novos preconceitos, porquanto se atém ao círculo dos círculos iniciados por um tutor que pôs sua canga sobre determinado aglomerado humano. Para a arraia miúda não se altera nada, com exceção dos personagens tutores. Por ser um evento no plano do fáctico, a revolução é contraposta pelo filósofo a um princípio normativo-racional, denominado Reform der Denkungsart (reforma no modo de pensar).

A grande massa (der grosse Haufen), insiste Kant, está enfarada com revoluções. Elas lhe dão tutores, sem os quais seria difícil viver, e se consola em ver que os novos tutores estão, eles próprios, sob o mesmo jugo que os antigos lhe haviam imposto. O Esclarecimento fica, portanto, nas mãos dos Selbstdenkenden. Apenas eles são promotores do Esclarecimento, somente neles a razão esclarecida encontra suportes históricos que não a passam para trás, ou seja, que não fazem com que a primeira natureza, dadivosa, se transforme em natureza opressora. Para Kant, homens esclarecidos fazem bem em não fazer revoluções. Eles devem estar comprometidos com a reforma do pensamento.

$\mathrm{Na}$ segunda seção de $\mathrm{O}$ conflito das faculdades, o filósofo alemão posiciona-se diante de um "acontecimento de nosso tempo" e chega a conclusões que alteram consagrados posicionamentos anteriores.

Embora mantenha a primazia do ponto de vista moral, o texto introduz argumentos até então ignorados no horizonte da moralidade kantiana. Kant escreve:

Este acontecimento não consta, digamos de açōes ou crimes importantes cometidos pelos homens [...]. Não, nada disso. É simplesmente o modo de pensar dos espectadores que se trai publicamente nesse jogo de grandes transformações, [...] e demonstra assim (por causa da universalidade) um caráter do gênero humano no seu conjunto e, ao mesmo tempo (por causa do desprendimento), um caráter moral [...] que nāo só permite esperar a progressāo, mas inclusive já constitui tal futuro progressivo, na medida em que se pode já agora obter o poder para tal. ${ }^{48}$

46 KANT. Beantwortung der Frage: was ist Aufklärung? Textos seletos. Ed. Bilíngüe. Petrópolis: Vozes, 1985, p. 105. "Durch eine Revolution wird vielleicht wohl ein Abfall von persönlichem Despotismus und gewinnsüchtiger oder herrschsüchtiger Bedrückung, aber niemals wahre Reform der Denkungsart zu Stande kommen".

47 Ibidem. "(S)ondern neue Vorurteile werden, eben sowohl als die alten, zum Leitbande des gedankenlosen grossen Haufens dienen".

48 Idem. Der Streit der Fakultäten. Hrsg. von K. Reich. Hamburg: Meiner, 1975, p. 84. "Diese Begebenheit besteht nicht etwa in wichtigen, von Menschen verrichteten Taten oder Untaten [...]. Nein: nichts von allem dem. Es ist bloss die Denkungsart der Zuschauer, welche sich bei diesem Spiele grosser Umwandlungen öffentlich verrät, und [...] so aber (der Allgemeinheit wegen) einen Charakter des Menschengeschlechts im ganzen und zugleich (der Uneigennutzigkeit wegen) einen moralichen Charakter desselben wenigstens in der Anlage beweiset, der das Fortschreiten zum Besseren nicht allein hoffen lässt, sondern selbst schon ein solches ist, soweit das Vermögen desselben für jetzt zureicht". 
O primado da moral continua de pé, a despeito do jogo de interesses imanente ao processo revolucionário. Por sua universalidade, o ocorrido demonstra um caráter moral, na disposição que denota. O visor moral não está, porém, mais fixado em atores, em ações ou em crimes de indivíduos. O fato de assim parecer deve-se ao modo de os espectadores entenderem aquilo que está ocorrendo. A Denkungsart deixa de ser privilégio de um punhado de sábios, para tornar-se o modo de ser de multidões. Objetivamente, o acontecimento não só aponta com maior ou menor segurança para o futuro - não, ele mesmo já é a progressão. Kant pondera: "a revolução [...] pode ter êxito ou fracassar, pode estar repleta de miséria e de atrocidades, de modo que um homem ponderado, se pudesse esperar, [...] jamais resolveria fazer o experimento com semelhantes custos". ${ }^{99} \mathrm{O}$ filósofo apostrofa enfático: "Essa revolução, [...] depara com uma participação segundo o desejo que beira o entusiasmo, cuja externação [...] não pode ter nenhuma outra causa senão uma disposição moral do gênero humano", ${ }^{50}$ sujeito jurídico e não biológico da história.

Enquanto signo histórico (signum rememorativum, demonstrativum, prognostikon), a Revolução Francesa tem no público espectador seu verdadeiro interpretante cuja solidariedade de ânimo com a humanidade, generalizada e desinteressada, determina culturalmente o que, no âmbito da razão prática, somente o respeito pela lei moral é capaz de desenvolver e fica à mão dos homens de boa vontade. Indiciadora de futuro, a Grande Revolução marca o take-off de uma nova ordem teórica, quer dizer, o direito de um povo de não ser impedido por outros poderes, ao dar-se uma constituição civil. O imperativo categórico persiste, o princípio do direito não o substitui ou limita, mas torna-se seu aliado. Enquanto o primeiro reporta-se à autoconsciência da existência - a duração de cada homem como ser vivente - o segundo abarca o devir, inconcebível sem alteridade e inimaginável sem gênero humano. Kant raciocina:

Não uma porção sempre crescente de moralidade na disposição de ânimo, mas na multiplicação de produtos de sua legalidade, em ações em conformidade ao dever, sejam quais forem os impulsos que as ocasionarem, isto é, nas boas ações dos homens que tornarão sempre mais numerosas e melhores, por conseguinte, nos fenômenos da constituição ética do gênero humano, tão-somente ai poder-se-á situar o ganho (o resultado) do cultivo do mesmo para melhor. ${ }^{51}$

49 Ibidem. "Die Revolution [...] mag gelingen oder scheitern; sie mag mit Elend und Greueltaten dermassen angefüllt sein, dass ein wohldenkender Mensch sie, wenn er sie zum zweitenmale unternehmend glücklich auszuführen hoffen könnte, doch das Experiment auf solche Kosten zu machen nie beschliessen würde [...]".

50 Ibidem. "(D)iese Revolution, [...] findet doch in den Gemütern aller Zuschauer [...] eine Teilnehmung dem Wunsche nach, die nahe an Enthusiasmus grenzt, und deren Ausserung [...] keine andere als eine moralische Anlage im Menschengeschlecht zur Ursache haben kann".

Ibidem, p. 91. "Nicht ein immer wachsendes Quantum der Moralität in der Gesinnung, sondem Vermehrung der Produkte ihrer Legalität in pflichtmässigen Handlungen, durch welche Triebfeder sie auch veranlasst sein mögen; d.i. in den guten Taten der Menschen, die immer zahlreicher und besser ausfallen werden, also in den Phänomenen der sittlichen Beschaffenheit des Menschengeschlechts, wird der Ertrag (das Resultat) der Bearbeitung desselben zum Besseren allein gesetzt werden können". 
O porvir ético da espécie é, para Kant, tributário de princípios internos do direito (innere Rechtsprinzipien), de acordo com os quais o fenômeno da Revolução Francesa, na ordem do tempo uma ocorrência causal, conjuga natureza e liberdade, um acontecimento que, segundo Kant, "nenhum político teria extraído do curso atual das coisas", 52 mas uma vez ocorrido, constitui "fenômeno na história da humanidade que não fica mais esquecida" ${ }^{53}$

\section{Observações conclusivas}

Somente através do ordenamento racional-jurídico o gênero humano percebe o progresso. $O$ fato de que a razão prática determina moralmente a vontade não é mais visto por Kant como único poder racional de regulação universal. A idéia de aglutinar a multiplicidade do querer humano pela legalização do agir externo dos homens, a qual não exige autocoerção, mas sim coexistência coativa sob o autodomínio da lei (Selbstherrschaft des Gesetzes), não perfaz uma "quimera vazia, mas é a norma eterna para qualquer constituição civil e afasta toda guerra", ${ }^{54}$ para Kant o empecilho por excelência da moral.

O regime normativo do direito, cujo alcance é a cultura humana, leva o filósofo alemão a inverter o curso das coisas, postulando que o progresso moral não se dá "de baixo para cima, mas de cima para baixo". ${ }^{55}$ Kant, um leitor entusiasta de Emile ou de l'éducation, vê com descrédito uma formação da juventude que se limita à instrução no lar e nas escolas e, reforçada pelo ensino religioso, acredita chegar, numa escala ascendente intelectual e moralmente, a não só educar bons cidadãos, mas educar para o bem o que ainda pode progredir e conservarse. "Tal plano", assegura Kant, "dificilmente permite esperar o êxito almejado". ${ }^{56}$ Com a Revolução Francesa a doutrina kantiana do direito é alçada a uma idéia da razão, quer dizer, torna-se possivel conhecer a priori as condições sob as quais seres que arbitram impulsos e inclinaçōes agem racionalmente. Tais condições, Kant as formula, ao escrever:

Caso se pudesse atribuir ao homem uma vontade inata e invariavelmente boa, embora limitada, ele poderia prognosticar com certeza a progressão de sua espécie para melhor, porque se trataria de um evento que ele mesmo pode efetuar. ${ }^{57}$

52 Ibidem, p. 87. "(K)ein Politiker aus dem bisherigen Laufe der Dinge herausgeklügelt hätte [...]".

53 Ibidem. "Denn ein solches Phänomen in der Menschengeschichte vergisst sich nicht mehr".

54 tbidem. "[... ist nicht ein leeres Hirngespinst, sondern die ewige Norm für alle bürgerliche Verfassung überhaupt, und entfernt allen Krieg".

55 Ibidem, p. 92. "Die Antwort ist: nicht durch den Gang der Dinge von unten hinauf, sondern den von oben herab".

56 Ibidem, 93. "[...] ist ein Plan, der den erwünschten Erfolg schwerlich hoffen lasst".

57 Bidem, p. 82. "Wenn man dem Menschen einen angebomen und unveränderlich-guten, obzwar eingeschränkten Willen beilegen dürfte, so würde er dieses Fortschreiten seiner Gattung zum Besseren mit Sicherheit vorhersagen können: weil es eine Begebenheit träfe, die er selbst machen kann". 
Já o Suplemento à Paz perpétua contém repetidas indicações de que princípios jurídicos-políticos são historicamente factíveis, porquanto o princípio moral no ser humano não se apaga jamais e a razāo encontra-se constantemente através da cultura em progresso permanente (fortschreitende Kultur); além disso, Kant afiança que "os princípios puros do direito têm realidade objetiva, isto é, são passiveis de execução". ${ }^{58}$ Em $O$ conflito das faculdades, por sua vez, após referir a narração histórica antecipadora àquilo que nos espera nos tempos futuros, o filósofo alemão explicita que se trata de "uma apresentação a priori possivel dos acontecimentos que devem estar por vir", e pergunta: "mas, como uma história a priori é possivel? Resposta: se aquele que antecipa o futuro faz e promove, por conta própria, os acontecimentos que anuncia" ${ }^{59} \mathrm{O}$ juízo sintético-prático a priori da história kantiana não consiste numa sustentação reflexiva, mas exemplarmente narrativa de que "o gênero humano esteve sempre em progresso para melhor e continuará a progredir da mesma maneira no futuro". ${ }^{60}$

Depois de passar para o plano da experiência e de afirmar que deve haver um acontecimento que remeta à constituição e à faculdade por parte do gênero humano de ser causa do progresso e autor do mesmo, o filósofo alemão constata que a partir de uma causa dada pode-se predizer um evento como efeito, quando ocorrem circunstâncias que concorram com o mesmo. Embora, em termos gerais, se possa saber assim, como no cálculo de probabilidades no jogo, que, em algum momento dado, configurar-se-ão ocorrências, é impossivel determinar se tal acontecimento ocorrerá em minha vida e se farei a experiência disso, confirmando a eventual predição. Necessário é, pois, procurar um evento que aponte para o estar-aí de tal causa e igualmente para o ato de sua causalidade no gênero humano, ainda que indeterminado quanto ao tempo. Ao identificar tal existência, seria possivel inferir, como conseqüência inelutável, a progressão e, assim, poder-se-ia ajuizar, escreve Kant, "a tendência do gênero humano no seu todo, isto é, não conforme os individuos [...], mas considerado segundo o modo como se encontra dividido em povos e Estados sobre o planeta". ${ }^{61}$

Tal demonstração contempla um conceito original da filosofia prática kantiana "de caráter misto", segundo Loparic, "pois designa, por um lado, a causa numenal que é a autora do progresso jurídico-político [...] e, por outro, os modos concretos

58 KANT. Zum ewigen Frieden 380. Hrsg. von H.-F. Klemme. Hamburg: Meiner, 1992, p. 96 "(D)ie reine Rechtsprinzipien haben objective Realität, d.i. sie lassen sich ausführen".

59 Idem. Der Streit der Fakultaten. Hrsg. von K. Reich. Hamburg: Meiner, 1975, p. 78. "Als wahrsagende Geschichtserzählung des Bevorstehenden in der künttigen Zeit: mithin als eine a prior mögliche Darstellung der Begebenheit, die da kommen sollen. - Wie ist aber eine Geschichte a prion moglich? - Antwort: Wenn der Wahrsager die Begebenheiten selber macht und veranstaltet, die er zum voraus verkündigt".

Ibidem, p. 88. "[...], dass das menschliche Geschlecht im Fortschreiten zum Besseren immer gewesen sei und so fernerhin fortgehen werde $[\ldots]^{\prime}$.

61 Ibidem, p. 83. "[...] und so die Tendenz des menschlichen Geschlechts im ganzen, di. nicht nach den Individuen betrachtet (..), sondern wie es in Völkerschaften und Staaten geteilt auf Erden angetroffen wird $[\ldots]^{\prime \prime}$. 
de manifestação dessa causa na história factual".$^{62}$ A novidade no âmbito da semântica dos juízos a priori políticos e históricos não consiste na idéia abstrata de vontade geral unificada, "mas", continua Loparic, "por ter elaborado a idéia de uma vontade geral sensificada, mais precisamente, o conceito de um sujeito coletivo da história", com tendência moral e jurídica para melhor, "dotado não apenas de propósitos e de capacidades de agir, mas também de outras faculdades até então comumente reservadas aos indivíduos, como a memória $[\ldots]]^{1 .}{ }^{63}$ A revolução dos franceses e a conquista da constituição republicana legitima, para Kant, a reivindicação moral da razão de que a espécie humana está a caminho, como sempre esteve, de um futuro melhor, vale dizer, a tipicidade maior da lei suprema do direito racional é a publicidade legalizadora da Revolução Francesa.

$O$ avanço específico do texto $O$ conflito das faculdades em relação à Doutrina do direito é que não são mais indivíduos, mas, sim, o gênero humano sobre o qual incidem a interpretação de conceitos puros práticos por conceitos puros teóricos do entendimento e a aplicação prática de conceitos puros práticos aos conceitos puros teóricos do entendimento por meio de esquemas puros e exemplos empírcos. De acordo com Loparic, "essa virada semântica [...] permite ao Kant tardio" compatibilizar natureza e liberdade com uma solução, "ao mesmo tempo racional e sensificada, em termos da teoria da exeqüibilidade física de princípios a priori de política moral $[\ldots]^{\prime \prime} .{ }^{64}$

Kant chega ao ápice do Esclarecimento, ou seja, à libertação da superstição. Essa consiste, para o filósofo alemão, no preconceito-mor de "representar-se a natureza como năo submetida a regras que o entendimento por sua própria lei essencial pōe-lhe como fundamento" ${ }^{65}$

\section{Referências}

ARENDT, Hannah. Lectures on Kant's political Philosophy. Chicago: The University of Chicago Press, 1982.

The life of mind. 2 v. New York: H. B. Jovanovich, 1978.

ARISTOTELES. Politics. Ed. by J. Bames. Princeton: University Press, 1995.

ARNOLD, Markus. Die harmonische Stimmung aufgeklärter Bürger, Zum Verhältnis von Politik und Ästhetik in Immanuel Kants "Kritik der Urteilskraft". Kant-Studien. Jhrg. 94, Heft 1, Berlim, 2003.

CICERO, Tulius, De officiis III, 6. Oeuvres completes. Trad. do latim por M. Nisard. Paris: Dislot, 1859, p. 85. (edição bilíngue).

${ }^{62}$ LOPARIC. O problema fundamental da semântica jurídica de Kant. WRIGLEY, M.-B e SMITH, P. (Org.). O filósofo e sua históna. Uma homenagem a Oswaldo Porchat. Campinas: Unicamp, Centro de Lógica, Epistemologia e História da Ciência, 2003, p. 513.

Ibidem, p. 515.

Ibidem, p. 518.

65 KANT. Kritik der Urteilskraft 158. Hrsg, von K. Vorländer. Hamburg: Meiner, 1968, p. 145. "Der Hang zur letzteren (zur passiven Vernunft, J.-N Heck), mithin zur Heteronomie der Vemunft, heisst das Vorurteil; und das grösste unter allen ist, sich die Natur Regeln, welche der Verstand ihr durch sein eigenes wesentliches Gesetz zum Grunde legt, als nicht unterworfen vorzustellen, d.i. der Aberglaube. Befreiung vom Aberglauben heisst Aufklärung". 
DUTRA, Delamar V. Kant e Habermas. A reformulação discursiva da moral kantiana. Porto Alegre: Edipucrs, 2002 (Coleção Filosofia).

FOUCAULT, Michel. "Ou' est-ce que les Lumières?". Dits et écrits IV (1980-1988). Paris: Gallimard, 1994.

GERHARDT, Volker. Immanuel Kants Entwurf "Zum ewigen Frieden". Eine Theorie der Politik. Darmstadt: Wissenschaftliche Buchgesellschaft, 1995.

Ausübende Rechtslehre. Kants Begriff der Politik. In: SCHÖNRICH \& KATO (Hrsg.). Kant in der Diskussion der Moderne. Frankfurt a/Main, 1996.

- Eine kritische Theorie der Politik über Kants Entwurf Zum ewigen Fnieden. In: ROHDEN (Org.). Kant e a instituiçäo da paz. Porto Alegre: Goethe-Institut, 1997.

GOUDELI, Kyriaki. Kant's Reflective Judgement: The Normalisation of Political Judgement. KantStudien. Jhrg. 94, Heft. 1, Berlim, 2003.

HABERMAS, Jürgen. Kants Idee des ewigen Friedens - aus dem historischen Abstand von 200 Jahren. In: Die Einbeziehung des Anderen. Studien zur politischen Theorie. 2. Aufl. Frankfurt a/Main: Suhrkamp, 1996.

HECK, José N. Direito e moral. Duas lições sobre Kant. Goiânia: Editoras UFG/UCG, 2000.

- Contratualismo e sumo bem politico. Um estudo preliminar sobre a pax kantiana. Porto Alegre. Veritas, v. 49, n. 1, 2004.

Autonomia, sentimento de respeito e Direito. Veritas. Porto Alegre, v, 46, n. 4, 2001.

HERB, Karlfriedrich. Bürgerliche Freiheit (Kant). Freiburg/München: Verlag K. Alber, 1999.

HÖFFE, Otfried. O imperativo categórico do direito: uma interpretação da "Introduçăo à Doutrina do Direito". Studia Kantiana, Rio de Janeiro, v. 1, n. 1, p. 203-234, 1998.

—. Ist Kants Rechtsphilosophie noch aktuell? Ders. (Hrsg.). Kant. Metaphysische Anfangsgründe der Rechtslehre. Berlin: Akademie Verlag, Bd. 19, (Reihe: Klassiker Auslege), 1999.

—. Gerechtigkeit. Eine philosophische Einführung. München: Verlag Beck, 2001.

- Kant als Theoretiker der intemationalen Rechtsgemeinschaft. In: SCHÖNRICH \& KATO (Hrsg.). Kant in der Diskussion der Modeme. Frankfurt a/Main: Suhrkamp, 1996.

—. Visão república mundial. Democracia na era da globalização. In: OLIVEIRA \& SOUZA (Org.). Justiça e política. Homenagem a Otfried Höffe. Porto Alegre: Edipucrs, 2003.

KANT, Immanuel. Metaphysische Anfangsgründe der Rechtslehre. Hrsg. von B. Ludwig. Hamburg: Meiner, 1986.

—. Kritik der praktischen Vernunft. Hrsg. von K. Vorländer. 9. Aufl. Hamburg: Meiner, 1967.

- Uber den Gemeinspruch (Vom Verhältnis der Theorie zur Praxis im Staatsrecht (gegen Hobbes); Vom Verhältnis der Theorie zur Praxis im Völkerrecht. In allgemein-philanthropischer, d.i. kosmopolitischer Absicht betrachtet (gegen Moses Mendelssohn). Hrsg. von H.-F. Klemme. Hamburg: Meiner, 1992.

—. Zum ewigen Frieden. Hrsg. von H.-F. Klemme. Hamburg: Meiner, 1992.

- Idee zur einer allgemeinen Geschichte in weltbürgerlicher Absicht. In: Kleiner Schriften zur Geschichtsphilosophie, Ethik und Politik. Hrsg. von K. Vorländer. Hamburg: Meiner, 1973.

Was heisst: sich im Denken orientieren?/Que significa: orientar-se no pensamento? In: Textos seletos . 2. Ed. Petrópolis: Vozes, 1985. 
- Beantwortung der Frage: Was ist Aufklärung?/Resposta à pergunta: que é 'Esclarecimento'? Textos seletos. 2. Ed. Petrópolis: Vozes, 1985.

. Kritik der Urteilskraft. Hrsg. von K. Vorländer, Hamburg: Meiner, 1968.

Der Streit der Fakultäten. Hrsg. von K. Reich. Hamburg: Meiner, 1975.

KAULBACH, F. Studien zur späten Rechtsphilosophie Kants und ihrer transzendentalen Methode. Würzburg: Königshausen \& Neumann, 1982.

. Das transzendental-juridische Grundverhälnis im Vernunftbegriff Kants und der Bezug zwischen Rechts und Gesellschaft. In: KAULBACH \& KRAWIETZ (Hrsg.). Rechts und Gesellschaft. Festschrift für H. Schelsky. Berlin: de Gruyter, 1988.

- Rechtsgehorsam und Gerechtigkeit bei Kant. In: KORFF, F.-W. (Hrsg.) Redliches Denken. Festschrift für G.-G. Grau. Stuttgart-Bad Cannstatt: Frommann Holzboog, 1982.

KELSEN, Hans. Reine Rechtslehre. 2. Neu bearb. und erweit. Auflage, 1960. Unveränd. Nachdruck. Wien: Franz Deuticke, 1983.

KERSTING, Wolfgang. Kant und der staatsphilosophische Kontraktualismus. Allgemeine Zeitschrift für Philosophie 8/1983.

. Politics, freedom, and order: Kant's political philosophy. In: GUYER, P. A companion to Kant. Cambridge, Mass. Cambridge University Press, 1992.

. Pax Kantiana. Towards a political philosophy of Intemational Relations. Archiv für Rechtsund Sozialphilosophie LXXX, 1994.

. Politische Philosophie der intemationalen Beziehungen. In: BAYERTZ, K. (Hrsg.). Politik und Ethik. Stuttgart: Reclam, 1996.

_. Globale Rechtsordnung oder weltweite Verteilungsgerechtigkeit? Über den systematischen Grundriss einer politischen Philosophie der internationalen Beziehungen. In: GERHARDT \& OTTMANN \& THOMPSON (Hrsg.). Politisches Denken. Jahrbuch 1995/6. Stuttgart: Metzler, 1995.

—. Die Gerechtigkeit zieht die Grenzen, und das gute setzt das Ziel. In: HÖFFE, O. (Hrsg.). John Rawls: Theorie der Gerechtigkeit. Berlin: Akademie Verlag (Reihe: Klassiker Auslagen), 1998.

Die Vertragsidee des Contrat social und die Tradition des neuzeitlichen. Kontraktualismus. In: BRANDT \& HERB (Hrsg.). Jean-Jacques Rousseau: Vom Gesellschaftsvertrag oder Prinzipien des Staatsrechts. Berlin: Akademie Verlag, (Reihe: Klassiker Auslegen), 2000.

Wohlgeordnete Freiheit. Immanuel Kants Rechts- und Staatsphilosophie. Frankfurt a/Main: Suhrkamp, 1993.

2002.

. Uber die Grenzen der Gerechtigkeit und der Moral. Weilerswist: Velbrück Wissenschaft,

- Jean-Jacques Rousseaus "Gesellschaftsvertrag". Darmstadt: Wissenschaftliche

Buchgesellschaft, 2002.

Modeme Freiheit IV: Liberale Eugenik, 2002 (mimeo).

KLEINGELD, Pauline. Kants politischer Kosmopolitismus. Jahrbuch für Recht und Ethik, Berlin, 1997.

KÖNIG, Peter. Autonomie und Autokratie. Über Kants Metaphysik der Sitten. Berlin/New York : de Gruyter, 1994.

LINDSTEDT, David. Kant: Progress in Universal History as a Postulate of Practical Reason. KantStudien. Jhrg. 90, Heft 2., Berlin, 1999. 
LOPARIC, Zeljko. O fato da razão. Uma interpretação semântica. Analytica. Rio de Janeiro, v. 4, n. 1, 1999.

. O problema fundamental da semântica juridica kantiana. WRIGLEY \& SMITH (Org.). O filósofo e sua históna. Uma homenagem a Oswaldo Porchat. Campinas: Unicamp, Centro de Lógica, Epistemologia e História da Ciência, 2003 (Col. CLE; v. 36).

LUDWIG, Bernd. Kants Rechtslehre. Hamburg: Meiner, 1988 (Kant-Forschungen).

RUEY, Patrick. Will and political legitimacy. Cambridge, Mass. University Press, 1982.

ROHDEN, Valerio. Sociabilidade legal. Uma ligaçăo entre direito e humanidade na 3. Crítica de Kant. In: Analytica, Rio de Janeiro: v. 1 n. 2, 1994. Institut, 1992

Razão prática e direito. In: ROHDEN (Org.). Racionalidade e açăo. Porto Alegre: GoetheTERRA, Ricardo. Passagens: estudos sobre a filosofia de Kant. Rio de Janeiro: Editora UFRJ, 2003.

1995.

. A politica tensa. Idéia e realidade na filosofia da histónia de Kant. São Paulo: Duminuras, 2, n. 1, 1997.

Foucault leitor de Kant: da antropologia à ontologia do presente. Analytica. Rio de Janeiro: v.

—. Juízo político e prudência em À paz perpétua. In: ROHDEN (Org.). Kant e a instituição da paz. Porto Alegre: Goethe-Institut, 1997.

WOOD, Allen W. Kant's doctrine of right: Introduction. In: Immanuel Kant. Metaphysische Anfangsgründe der Rechtslehre. Hrsg. von O. Höffe. Berlin: Akademie Verlag, 1999 (Klassiker Auslegen). 